\title{
Heterogeneity in the Second Internal Transcribed Spacer (ITS2) of rDNA in the Genetically Distinct Metopolophium dirhodum Isofemale Lineages (Hemiptera: Aphididae)
}

\author{
Marcelo Lopes-da-Silva1, Luiz Gonzaga Esteves Vieira² \\ ${ }^{1}$ Plant Quarantine Laboratory, Embrapa Genetic Resources and Biotechnology, Brazilian Agriculture Research \\ Corporation (Embrapa), Brasília DF, Brazil \\ ${ }^{2}$ University of Western São Paulo (Unoeste), Presidente Prudente, Brazil \\ Email: marcelo.lopes.silva@embrapa.br
}

Received 12 August 2014; revised 18 September 2014; accepted 8 October 2014

Copyright (C) 2014 by authors and Scientific Research Publishing Inc.

This work is licensed under the Creative Commons Attribution International License (CC BY).

http://creativecommons.org/licenses/by/4.0/

(c) (i) Open Access

\section{Abstract}

The aim of this study was to investigate the level of evolutionary divergence among five isofemale lineages of Metopolophium dirhodum Walker (Hemiptera: Aphididae) using sequences of the Internal Transcribed Spacer (ITS) of ribosomal DNA (rDNA). These isofemalelineages were derived from parthenogenetic females, previously genetically characterized by having strong association of RAPD (Random Amplified Polymorphic DNA) molecular markers and host plant preference. Out of 25 sequences, only 17 containing ITS2 (the second spacer) were used for analysis due to their quality. Within 250 nucleotide sites originated by multiple alignments, $10.4 \%$ were variable, with the predominance of indels over substitutions. The average of nucleotide diversity $(\pi)$ within isofemale lineages was similar to the diversity found among all isofemale lineages. The topology inferred by the Neighbor-Joining method showed that no evolutionary divergence inferred by ITS2 sequences among isofemale lineages typified by RAPD could be associated with host preference. The ITS2 sequence differences found within lineages and their causes are discussed.

\section{Keywords}

Aphid, Clones, Molecular Evolution, DNA 


\section{Introduction}

Metopolophium dirhodum (Walker, 1849) is an important pest of cereals, not only because of the direct damage that this aphid causes by sap suction but also indirectly by transmission of plant virus and losses in cereal production are reported between 7\% - $17 \%$ [1]. The presence of $M$. dirhodum in South America was first reported in the 1970s in Chile and Brazil, where it became the major pest of wheat [2].

There are no records of the occurrence of the sexual phase in Brazil [3] and few studies on the genetic diversity of $M$. dirhodum have been carried out in comparison with other cereals aphids worldwide. For instance, absence of correlation between genetic polymorphisms and host preference in Southern England was reported [4]. In another study, the genetic variability of introduced populations of $M$. dirhodum in New Zealand is low when compared with populations from Scotland [5]. However, in southern Brazil, the presence of two karyotypes within populations of $M$. dirhodum $(2 \mathrm{n}=16$ and $2 \mathrm{n}=18)$ was reported, showing an important genetic divergence caused by chromosomal rearrangements [6].

Insect species that cyclically alternate sexual and asexual phases, as aphids, provide an excellent opportunity to study changes in multi-gene families, which may have arisen after reproductive isolation periods [7]. The ribosomal DNA of eukaryotes (rDNA) is a multi-gene family arranged in repeated units, each containing ribosomal RNA genes that are separated by two internal transcribed spacers (ITS): the ITS1, located between 18S and 5.8S ribosomal genes, and ITS2, which separates 5.8S gene and 28S ribosomal genes [8]. While ribosomal genes are highly conserved within species, ITS sequences can be intra-specifically variable. Ribosomal genes and spacers are not subjected to the same selection intensity. ITS evolves much faster than ribosomal genes and more slowly than intergenic spacer region (IGS) [8]. The ITS region have been used as molecular clocks to estimate divergence times among taxons. The rate of base substitutions observed within ITS2 sequences for the majority of organisms ranges from $0.3 \%$ to $0.8 \%$ per million of years [9].

In parthenogenetic organisms, rDNA may be homogeneous due to recombination [10], but after a long cycle of apomictic generations, differences in nucleotide sequences between alleles are acquired [11]. In that case, if concerted evolution is less efficient in the homogenization of the nucleotide sequence of ITS. Some level of variation might be found among multiple copies of genes within parthenogenetic individuals [12]. For example, the large part of the variation in the ITS1 sequence (80\% of the total) in Darwinula stevensoni (Crustacea), an asexual organism, was found within individuals [12]. There is a report about intragenomic variation within ITS1 sequence, which originated an existence of two haplotypes within Myzus persicae (Sulzer) individual [13].

Despite variation of ITS, which is a limitation for phylogenetic studies of closely related species, ITS1 and ITS2 sequences are useful to detect cryptic species or even species before their formal description [14].

The primary interest of this investigation was to verify the existence of intragenomic variability in the internal transcribed spacer sequence of rDNA within and among isofemales lineages (clonal lineages derived from a single female clone) collected in cereal producing regions in southern Brazil [3]. Genetic polymorphisms were found in $M$. dirhodum clones strongly correlated with the host-plant where the aphids were collected, which suggests that the hypothesis of host-races (one associated with wheat and the other associated with oats) should be investigated [3].

\section{Material and Methods}

\subsection{Selection of Aphid Clonal Populations}

The aphid lineages used in this work were selected based on their differences in the RAPD profiles, which DNA polymorphisms showed a strong relationship to the host-plant field preference of individual clones [3]. The original clones were collected from wheat and oat fields in Rio Grande do Sul State, Brazil (Table 1). One female collected on wheat (J. Lage, personal information) obtained from CIMMYT (El Batan-México) was included in the analysis for comparison. All clones were reared on their original field host (wheat or oats) in vases under greenhouse conditions. In order to avoid parasitism, the plants were protected by transparent acrylic tubes, whose tops were covered by fabric [3].

\subsection{DNA Extraction and ITS Amplification}

DNA extraction was performed according to Carvalho and Vieira's protocol [15], with slight modifications in order to get the best performance for DNA extraction. All conditions were tested before to bioassays to assure 
Table 1. Metopolophium dirhodum clonal lineages. Field and sequencing data.

\begin{tabular}{cccc}
\hline \multirow{2}{*}{$\begin{array}{c}\text { Clonal } \\
\text { lineage ID }\end{array}$} & \multicolumn{3}{c}{ Field and sequencing data } \\
\cline { 2 - 4 } O6 & Sequence codes & Collection site & Genbank accession \\
O14 & O6-1, O6-2, O6-3, O6-4 & Panambi, RS, Brazil & EU685264, EU685265, EU685266, EU685267 \\
W7 & O14-1, O14-2, O14-3 & Selbach, RS, Brazil & EU685268, EU685269, EU685270 \\
W9 & W7-1, W7-2 & Ijuí, RS, Brazil & EU685254, EU685255 \\
W10 & W10-1, W10-2, W10-3, W10-4, W10-5 & El Batan, Mexico & EU685259, EU685260, EU685261, EU685262, EU685263 \\
\hline
\end{tabular}

DNA extraction with reasonable quality for analysis. Five clones of each lineage from a single parthenogenetic female were macerated in $1.5 \mathrm{~mL}$ microtubes with a $200 \mu \mathrm{L}$ extraction buffer $(200 \mathrm{mM}$ Tris-HCl, $\mathrm{pH}$ 8.0; $2 \mathrm{M}$ $\mathrm{NaCl} ; 0.5 \mathrm{M}$ EDTA) and $50 \mu \mathrm{L}$ sarcosyl. The resultant suspension was heated on a warming plate $\left(65^{\circ} \mathrm{C}\right)$ for 30 min and centrifuged at 10,000 rpm for $15 \mathrm{~min}$. The supernatant was poured into a new microtube, and $110 \mu \mathrm{L}$ ammonium acetate $(10 \mathrm{M})$ with $250 \mu \mathrm{L}$ cold isopropanol was added and both are necessary for DNA precipitation at $-20^{\circ} \mathrm{C}$ for $8 \mathrm{~h}$. After a freezing process, the microtubes were centrifuged at 10,000 rpm during 15 min. The DNA pellets were washed with 70\% ethanol, re-suspended by addition of a $25 \mu \mathrm{L}$ TE buffer (Tris-EDTA, $\mathrm{pH} 8.0$ with RNAse) and then stored at $-20^{\circ} \mathrm{C}$. The PCR reactions were carried out in $0.6 \mathrm{~mL}$ microcentrifuge tubes containing $400 \mu \mathrm{M}$ of dNTP, $2.5 \mu \mathrm{M}$ of primers ITS-4: 5'-TCCTCCGCTTTATTGATATGC-3' and ITS-5: 5'AAGTAAAAGTCGTAACAAGG-3' [16], 1.25 U Taq polymerase to replicate DNA in vitro during Polymerase Chain Reaction (PCR) and buffer (10 mM Tris-HCl, $3 \mathrm{mM} \mathrm{MgCl}_{2}, 50 \mathrm{mM}$ de KCl, pH 8.3). The amplifications were performed in a thermocycler (MJ Research, model PTC- $100^{\mathrm{TM}}$ ) using the following program: 3 min at $95^{\circ} \mathrm{C}$, followed by 35 cycles for $1 \mathrm{~min}$ at $95^{\circ} \mathrm{C}, 1 \mathrm{~min}$ at $55^{\circ} \mathrm{C}$ and $2 \mathrm{~min}$ at $72^{\circ} \mathrm{C}$, with the final extension of 5 $\min$ at $72^{\circ} \mathrm{C}$. The amplified fragments length was estimated at being around $900 \mathrm{bp}$.

\subsection{DNA Cloning}

After gel staining with ethidium bromide, the band was excised by the "freezing-thaw" method, and recovered inside a $1.5 \mathrm{~mL}$ microtube and DNA was precipitated using sodium acetate $3 \mathrm{M}(\mathrm{pH} 5.2,10 \% \mathrm{v} / \mathrm{v})$ and $2 \times$ the amount of absolute ethanol at $0^{\circ} \mathrm{C}$. After centrifugation (10,000 rpm) for $5 \mathrm{~min}$, the precipitate was washed with $200 \mu \mathrm{L}$ ethanol 70\% and dried at room temperature. DNA was re-suspended in $10 \mu \mathrm{L}$ TE buffer + RNAse. The fragment of the ITS2 region was cloned using the vector PCR 2.1-TOPO ${ }^{\circledR}$ cloning kit (Invitrogen ${ }^{\mathrm{TM}}$ ), according with manufacturer's specifications and inserted in the Escherichia coli strain DH5- $\alpha$ by electroporation. Five transformed clones per Petri dish were selected each one representing one copy of ITS2 of each isofemale lineage of M. dirhodum. Plamidial DNA was extracted by alkaline lise [17] and sequencing was made in the Mega BACE 1000 DNA Analysis System (GE Life Science) using the reverse primer M13 (5'-AGGAAACAGCTATGAC-3'). Each clone was sequenced three times to assure that the scored bases were not products of PCR errors.

\subsection{Data Analyses}

DNA sequence alignments were performed using the Clustal W package with a gap-opening penalty of 5 and a gap-extension penalty of 2. Manual adjustments were made with the BioEdit software [18].

Nucleotide diversity $(\pi)$ was calculated as: $\pi=\Pi / L$, where $\Pi=$ average nucleotide differences between two sequences randomly taken from the population and $L=$ length of sequence (number of nucleotides) [19]. With "n" sequences, $\Pi$ was calculated by the following formula: $\Pi=1 /[n(n-1) / 2] \times \Sigma_{\mathrm{i}}<{ }_{\mathrm{j}} \Pi_{\mathrm{ij}}$ where $\Pi_{\mathrm{ij}}$ is number of differences between "i” and " $\mathrm{j}$ " sequences, being $\mathrm{n} /(\mathrm{n}-1) / 2$ the number of possible pairs of all sequences analyzed [20]. The nucleotide diversity was calculated within sequences of the same clonal lineage and between sequences of different clonal lineage. Gaps were considered as a fifth base.

The phylogenetic tree was drawn using the MEGA 2.1 software (Molecular Evolution Genetic Analysis) [21] based on the Neighbor-Joining (NJ) distance method [22]. The distance between pairs of sequences was obtained by the Kimura Two-Parameters model, with transition/transversion ratio $=2$, excluding gaps originated by multiple alignments. The same model was used to calculate the distances within and between clonal lineages. 
Confidence in estimated relationships was determined using the bootstrap approach and it was obtained using 5000 replicates.

Acyrthosiphon pisum Harris (Hemiptera: Aphididae) was chosen as an out-group because it is the species which is phylogenetically most closely related to M. dirhodum [23].

\section{Results and Discussion}

\subsection{Size and Composition}

From 25 sequences obtained, only 17 were utilized for ITS2 analysis due to their sequence quality. Although sequence information of over 900 bp from the internal transcribed spacer region (ITS1, 5.8S and ITS2) was obtained, only sequences from the ITS2 region were considered in this study. These sequences ranged from 236 to $243 \mathrm{bp}$, resulting in 250 positions suitable for analysis in multiple alignments.

The sequences differed by six substitutions (three transversions and three transitions) and they presented 21 indels. In the position 221 of multiple alignment was observed a substitution and a deletion. Differently from human lice (P. humanus) where the occurrence of deletions of $10-25$ bp has been reported [24], the indels in ITS2 sequences of $M$. dirhodum are mainly constituted of small deletions (one or two bases). Indels were also found in the ITS region of other aphid species, like Myzus persicae [13] where intra-individual variation in ITS1 was found, but comparatively, the ITS sequences of M. dirhodum are more variable. The intragenomic variation of M. dirhodum ITS2 has a level similar to ITS2 of the cestoda worm Caryophyllaiedes fennica, which 13 different ITS2 sequences were obtained from three individuals [25]. However, the level of intra-individual variation of ITS found in M. dirhodum is relatively low when it is compared with variation found in the corals, which level can reach $30 \%$ among sequences [26].

The nucleotide composition of the M. dirhodum ITS2 partial fragment reveals a predominance of C:G (approximately 70\%). The predominance of C:G over A:T in the ITS region is common, with the exception of Drosophila, where the percentage of G:C content of the ITS2 ranges from 18\% to 26\% [27]. The analysis of other ITS sequences from aphids present in the GenBank shows that the predominance of G:C over A:T in the ITS region and it seems to be a general rule for this insect group (data are not showed).

Overall, the most divergent distance between lineages was the pair W9-W10 (they shared the same host). The less divergent was W7-014 (isofemales from different host species). The Mexican line (W3) had greatest genetic distances among their sequences and also from sequences of other isofemale lines (Table 2, Table 3).

The average ITS2 nucleotide diversity within an isofemale lineage was similar to the diversity found among the five lineages. Within the clonal lineages previously characterized by RAPD, the lowest nucleotide diversity was within lineage W9 $\left(\pi_{\mathrm{i}}=1.3 \%\right)$, and the highest within clonal lineage O14 $\left(\pi_{\mathrm{I}}=3.3 \%\right)$. Between clonal lineages, the highest $\pi$ was found within pairs that contained O14 lineage, especially the sequence pair O14-1 and O6-2 $(\pi=5.0 \%)$.

These results showed that the nucleotide diversity within the ITS2 region of M. dirhodum is distributed homogeneously within $\left(\pi_{\mathrm{i}}\right)$ and among lineages $\left(\pi_{\mathrm{e}}\right)$ (Table 4). Similar distribution was found in D. stevensoni (Crustacea: Ostracoda) by [12] On the other hand, intragenomic variation has $85 \%$ - 91\% of total variation rDNA in Chortippus paralellus (Orthoptera: Acrididae) [28].

The amount of variable sites found within ITS2 sequences of $M$. dirhodum clonal lineages analyzed in this work (10.4\%) was less than that found in Pediculus humanus (34.4\%) [24], but similar to that obtained by for Ixodes scapularis (Acari) [29]. The only report about intragenomic ITS sequence variation within aphids reveals

Table 2. Distances (D) estimated by Kimura two-parameters of sequences within same clonal lineage.

\begin{tabular}{|cc|}
\hline Clonal Lineage ID & D \\
\hline O6 & 0.00425 \\
O14 & 0.00281 \\
W7 & 0.00768 \\
W9 & 0.00212 \\
W10 & 0.00564 \\
\hline
\end{tabular}


Table 3. Mean paired distances estimated by Kimura two-parameters among clonal lineages of Metopolophium dirhodum.

\begin{tabular}{cccccc}
\hline & O6 & O14 & W7 & W9 & W10 \\
\hline O6 & 0.00000 & & & & \\
O14 & 0.00282 & 0.00000 & & & \\
W7 & 0.00318 & 0.00211 & 0.00000 & 0.00000 & 0.00000 \\
W9 & 0.00495 & 0.00423 & 0.00390 & 0.00797 & 0.00620 \\
W10 & 0.00725 & 0.00596 & & \\
\hline
\end{tabular}

Table 4. Index of nucleotide diversity of partial sequences of ITS2 from five clonal lineages of Metopolophium dirhodum.

\begin{tabular}{rcc}
\hline Index & Value (\%) \\
\hline$\pi_{i}$ & $\pi_{\varepsilon}$ & 1.98 \\
$\pi_{t}$ & 1.83 & 1.74 \\
\hline
\end{tabular}

the existence of six-point mutations within ITS1 of $M$. persicae [13]. The rate of substitution reported is similar to that found in the ITS2 sequences of $M$. dirhodum in this present work.

Some organisms have highly conserved ITS2 sequences, such as Drosophila (Diptera) species [27], which shows that concerted evolution is very efficient for homogenization of a gene present in many copies. In a different way, as demonstrated here, aphids can carry variation within their ITS copies. The intragenomic sequence variation is not a particular characteristic of parthenogenetic organisms. Intragenomic heterogeneity of the ITS regions was already observed in many different organisms The extent varies considerably between taxa and it is presumed to arise by mechanisms such as slipped strand mispairing events. Also, in parthenogenetic organisms such as aphids, the absence of meiosis limits heteroduplex molecules formations that are need for homogenization of paralogs copies [12]. Intragenomic polymorphism in rDNA is much more common than was previously reported and reports showed that concerted evolution is not working to homogenize sequences of rDNA of many organisms, such ascomycetes fungus [30] and based on our results, this occurs in aphids also.

Variation is not found only in non-coding regions as ITS, IGS and External Transcribed Spacers and a highly divergent rDNA groups was found within single individuals of Podisma pedestris (Orthoptera: Acrididae) [31]. Further studies are still needed to determine the existence and the extent of intragenomicvariation on coding-regions of rDNA of $M$. dirhodum. The variation was found only in the ITS regions and none variation in the sequences of 5.8S gene was observed, but the analysis in other coding regions (18S and 28S) by limitation of primers set utilized.

\subsection{Phylogenetic Analysis}

The consensus bootstrap neighbor-joining tree obtained after 1000 bootstraps replicates indicated that the hypothesis of monophyly associated to the host plant should be rejected (Figure 1).

Host-race evolution is described in grass aphids like Schizaphis graminum (Rondani) which divergence among sequences of cytochrome oxidase I (mitochondrial gene) among biotypes were consistently observed [30]. S. graminum is considered a case of host-races that diverged in consequence of coevolution with non-crops [30] and this does not seem to be the case of $M$. dirhodum. The host-race existence in $M$. dirhodum in Brazil could be the result of a recent event of selection imposed by hosts on introduced populations. As RAPD markers can be associated with adaptative polymorphisms [31], there is a greater probability to find RAPD polymorphisms associated to host-plant preference than finding divergences in the sequences of ribosomal or mitochondrial DNA [3] [32]-[34].

The particularities of aphid reproduction systems have important evolutionary consequences. The genetic variation that appears within obligatory parthenogenetic clones is not caused only by mutations. Exclusively asexual lineages can produce males, which only mate with females of sexual lineages, giving rise to new asexual and sexual lineages [35]. It is known that the ribosomal DNA of aphids is confined to sexual chromosomes (X 


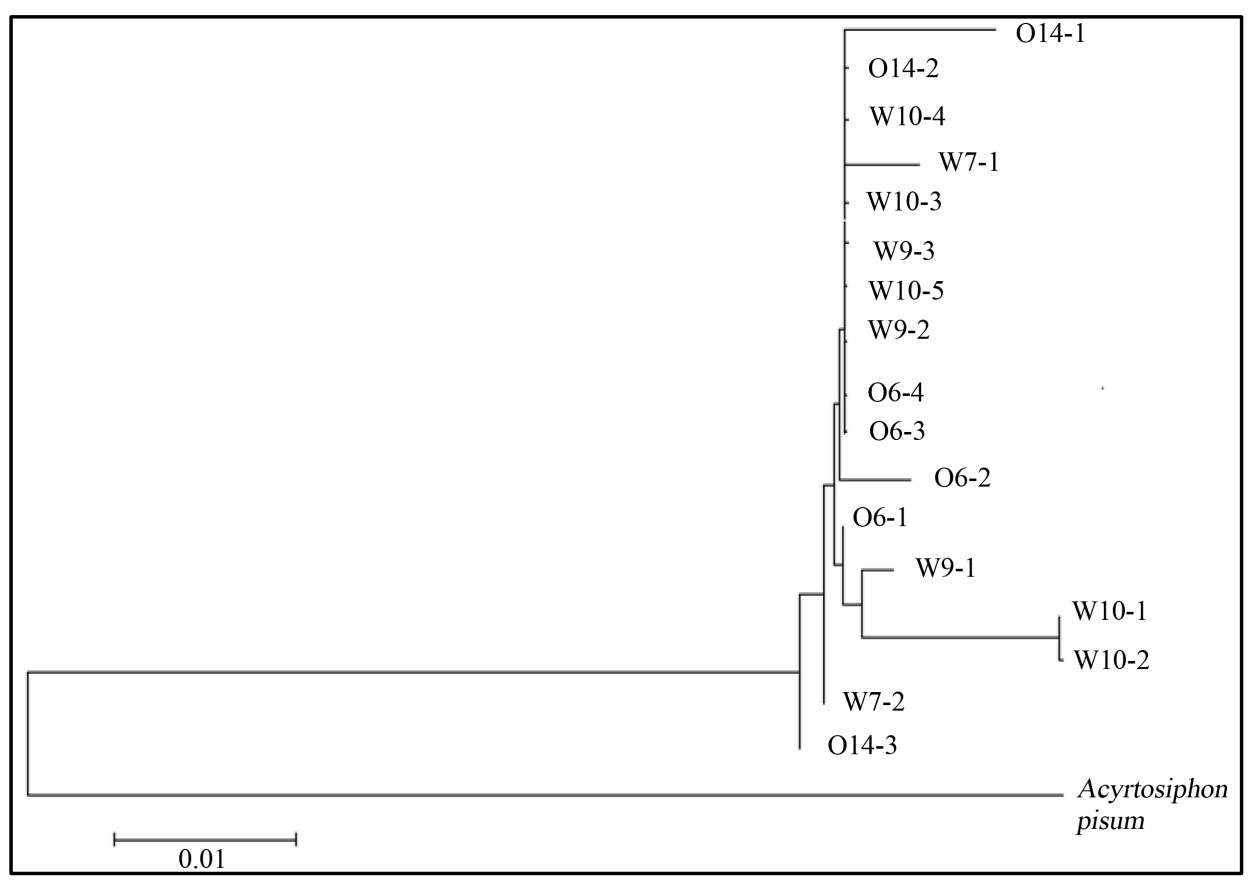

Figure 1. Rooted three obtained by the Neighbor Joining method showing phylogenetic relationship among ITS2 haplotypes of Metopolophium dirhodum. The distance model used was Kimura-Two parameteres. A. pisum was used as an outgroup (accession Genbank sAF024644).

chromosomes) [36]. Females (with XX chromosomes) originating from the mating of males of asexual lineages with females of sexual lineages can have two sets of rDNA with divergence at the time of separation between sexual and obligatory asexuals. Another possible explanation for ITS intragenomic variation in aphids is interspecific hybridization. However, there are only two reports of inter-specific crosses inferred by DNA analysis: Sitobion avenae $\times$ Sitobion fragariae [37] and asexual hybrid lineages of Rhopalosiphum padix cryptic species of Rhopalosiphum [38]. No satisfactory explanations on the mechanisms responsible for the variation found in the rDNA of parthenogenetic organisms such as aphids were proposed [39].

In this present work, it was showed for the first time that intragenomic ITS2 sequence variation occurs within M. dirhodum. This finding lends support to the hypothesis of rapid changes in clonal lineages of aphids [40].

The variation in ITS2 sequences of the ITS2 region in M. dirhodum populations collected in southern Brazil suggests that concerted evolution has not homogenized all rDNA copies within individuals. Despite the level of intragenomic variation found, based on information obtained from ITS2 sequences, the previously RAPD typified isofemales lineages are not evolutionary divergent by host use or preference.

High diversity in ITS regions of rDNA is a clear indication of occurrence of sexual phase in M. dirhodum at certain level. In the case of aphids, this can be a source of new clonal variants and high probability of emergence of new-host races. This aspect of biology of M. dirhodum in South America is important especially for plant breeding programs to incorporate resistance to this pest.

\section{Acknowledgements}

We are indebted to Hugo Bruno Molinari and Elizabeth Keiko Takahashi for their assistance in the work of cloning and sequencing and, Rick Harder for his review of this article.

\section{References}

[1] Ul-Haq, E. (2003) Interaction between Biological Control and Cultural Control of Metopolophium dirhodum (Walker) on Wheat. Pakistan Journal of Biological Sciences, 6, 1009-1020. http://dx.doi.org/10.3923/pjbs.2003.1009.1020

[2] Zuñiga, E. (1986) Control Biológico de los Afidos de los Cereales en Chile. I. Revisión histórica y Líneas de Trabajo. Agricultura Tecnica, 46, 475-477. 
[3] Lopes-da-Silva, M. and Vieira, L.G.E. (2007) Analysis of the Genetic Diversity in Metopolophium dirhodum (Walker) (Hemiptera: Aphididae). RevistaBrasileira de Entomologia, 51, 54-57. http://dx.doi.org/10.1590/S0085-56262007000100009

[4] De Barro, P., Sherrat, T.N., Carvalho, G.R., Nicol, D., Yengar, A. and McClean, N. (1995) The Use of Multilocus (GATA) ${ }_{4}$ Probe to Investigate Geographic and Microgeographic Genetic Structure Variation in Two Aphid Species over Southern England. Molecular Ecology, 4, 375-382.

http://onlinelibrary.wiley.com/doi/10.1111/j.1365-294X.1995.tb00230.x/abstract

[5] Nicol, D., Armstrong, K.F., Wratten, S.D., Cameron, C.M., Frampton, C. and Fenton, B. (1997) Genetic Variation in an Introduced Aphid Pest (Metopolophium dirhodum) in New Zealand and Relation to Individuals from Europe. Molecular Ecology, 6, 255-265. http://onlinelibrary.wiley.com/doi/10.1046/j.1365-294X.1997.00179.x/abstract

[6] Rubin-de-Celins, V., Gassen, D.N., Santos-Colares, M.C.,Oliveira, A.K. and Valente, V.L.S. (1997) Chromosome Studies in Southern Brazilian Wheat Pest Aphids Sitobionavenae, Schizaphis graminum, Methopolophium dirhodum (Homoptera: Aphididae). Brazilian Journal of Genetics, 20, 415-419. http://dx.doi.org/10.1590/S0100-84551997000300010

[7] Black, W.C. (1993) Variation in the Ribosomal RNA Cistron among Host-Adapted Races of an Aphid (Schizaphis graminum). Insect Molecular Biology, 2, 59-69. http://onlinelibrary.wiley.com/doi/10.1111/j.1365-2583.1993.tb00126.x/abstract

[8] Zhao, Y.E., Hu, L.P., Hu, L., Xu, Y., Wang, Z.H., Liu, W.X., Wang. Z.H. and Liu, W.Y. (2012) Sequencing for Complete rDNA Sequences (18S, ITS1, 5.8S, ITS2, and 28 S r DNA) of Demodex and Phylogenetic Analysis of Acari Based on 18S and 28S rDNA. Parasitology Research, 111, 2109-2114. http://dx.doi.org/10.1007/s00436-012-3058-8

[9] Bargues, M.D., Marcilla, A., Ramsey, J.M., Dujardin, J.P., Schofield, C.J. and Mas-Coma, S. (2000) Nuclear rDNA-Based Molecular Clock of the Evolution of Triatominae (Hemiptera, Reduviidae), Vectors of Chagas Disease. Memórias do Instituto Oswaldo Cruz, 95, 567-573. http://dx.doi.org/10.1590/S0074-02762000000400020

[10] Kajtoch, T. and Lachowska-Cierlik, D. (2009) Genetic Constitutition of Parthenogenetic Form of Polydrususinustus (Coleoptera: Curculioniade)—Hints of Hybrid Origin and Recombinants. Folia Biologia, 57, 149-156. http://dx.doi.org/10.3409/fb57_3-4.149-156

[11] Fuertes-Aguilar, J., Roselló, J.A. and Nieto Feliner, G. (1999) Nuclear Ribosomal DNA (nrDNA) Concerted Evolution in Natural and Artificial Hybrids of Armeria (Plumbaginaceae). Molecular Ecology, 8, 1341-1346.

http://onlinelibrary.wiley.com/enhanced/doi/10.1046/j.1365-294X.1999.00690.x/ http://dx.doi.org/10.1046/j.1365-294X.1999.00690.x

[12] Gandolfi, A., Bonilauri, P., Rossi, V. and Menozzi, P. (2001) Intraindividual and Intraspecies Variability of ITS1 Sequences in the Ancient Asexual Darwinula stevensoni(Crustacea: Ostracoda). Heredity, 87, 449-455. http://www.nature.com/hdy/journal/v87/n4/abs/6889270a.html http://dx.doi.org/10.1046/j.1365-2540.2001.00927.x

[13] Fenton, B., Malloch, G. and Germa, F. (1998) A Study of Variation in rDNA ITS Regions Shows that Two Haplotypes Coexist within a Single Aphid Genome. Genome, 41, 337-344. http://www.nrcresearchpress.com/doi/pdfplus/10.1139/g98-030 http://dx.doi.org/10.1139/g98-030

[14] Litaker, R.W., Vandersea, M.W., Kibler, S.R., Reece, K.S., Stokes, N.A., Lutzoni, F.M., Yonish, B.A., West, M.A., Black, M.N.D. and Tester, P.A. (2007) Recognizing Dinoflagellate Species Using ITS rDNA Sequences. Journal of Phycology, 43, 344-355. http://onlinelibrary.wiley.com/enhanced/doi/10.1111/j.1529-8817.2007.00320.x/ http://dx.doi.org/10.1111/j.1529-8817.2007.00320.x

[15] Carvalho, A.O.C. and Vieira, L.G.E. (2001) Determinação das condições ótimas para análises de PCR-RAPD em Atta sexdens rubropilosa Forel. (Hymenoptera: Formicidae). Neotropical Entomology, 30, 593-600. http://dx.doi.org/10.1590/S1519-566X2001000400013

[16] White, T.J., Bruns, T., Lee, S. and Taylor, J. (1990) Amplification and Direct Sequencing of Fungal Ribosomal RNA Genes for Phylogenetics. In: Innis, M.A., Gelfand, D.H., Sninsky, J.J. and White, T.J., Eds., PCR Protocols: A Guide to Methods and Applications, Academic Press, London, 315-322.

[17] Sambrook, J., Fritsch, E.F. and Maniatis, T. (1989) Molecular Cloning: A Laboratory Manual. 2nd Edition, Cold Spring Harbor Laboratory Press, New York.

[18] Hall, T. (1997) BioEdit: Biological Sequence Alignment Editor for Win95/98/NT/2K/XP/7. www.mbio.ncsu.edu/BioEdit/bioedit.html

[19] Nei, M. and Li, W.H. (1979) Mathematical Model for Studying Genetic Variation in Terms of Restriction Endonucleases. Proceedings of the National Academy of Sciences of the United States of America, 76, 5269-5273. http://dx.doi.org/10.1073/pnas.76.10.5269

[20] Li, W.H. (1997) Molecular Evolution. Sinauer, Massachusetts. 
[21] Kumar, S., Tamura, K., Jakobsen, I.B. and Nei, M. (2001) MEGA2: Molecular Evolutionary Genetics Analysis Software. Bioinformatics, 17, 1244-1245. http://dx.doi.org/10.1093/bioinformatics/17.12.1244

[22] Saitou, N. and Nei, M. (1987) The Neighbor-Joining Method: A New Method for Reconstructing Phylogenetic Trees. Molecular Biology and Evolution, 4, 406-425.

[23] Blackman, R.L. and Eastop, V.F. (1984) Aphids on the World’s Crops: Identification and Information Guide. John Wiley Sons, London, 476 p.

[24] Leo, N.P. and Baker, S.C. (2002) Intragenomic Variation in ITS2 rDNA in the Louse of Humans, Pediculus humanus: ITS2 Is Not a Suitable Marker for Population Studies in this Species. Insect Molecular Biology, 11, 651-657. http://onlinelibrary.wiley.com/doi/10.1046/j.1365-2583.2002.00367.x/abstract http://dx.doi.org/10.1046/j.1365-2583.2002.00367.x

[25] Orosová, M., Ivica, K.H., Eva, B. and Marta, Š. (2010) Karyotype, Chromosomal Characteristics of Multiple rDNA Clusters and Intragenomic Variability of Ribosomal ITS2 in Caryophyllaeides fennica (Cestoda). Parasitology International, 59, 351-357. http://dx.doi.org/10.1016/j.parint.2010.04.007

[26] LaJeunesse, T. and Pinzón, J.H. (2007) Screening Intragenomic rDNA for Dominant Variants Can Provide a Consistent Retrieval of Evolutionarily Persistent ITS (rDNA). Molecular Phylogenetics and Evolution, 45, 417-422. http://dx.doi.org/10.1016/j.ympev.2007.06.017

[27] Torres, R.A., Ganal, M. and Hemleben, V. (1990) GC Balance in the Internal Transcribed Spacers ITS1 and ITS2 of Nuclear Ribosomal RNA Genes. Journal of Molecular Evolution, 30, 170-181. http://dx.doi.org/10.1007/BF02099943

[28] Parkin, E.J. and Butlin, R.K. (2004) Within and Between-Individual Sequence Variation among ITS1 Copies in the Meadow Grasshopper Chortippus paralellus Indicates Frequent Intrachromosomal Gene Conversion. Molecular Biology and Evolution, 21, 1595-1601. http://mbe.oxfordjournals.org/content/21/8/1595.full.pdf+html http://dx.doi.org/10.1093/molbev/msh163

[29] Risch, S.M., Rosenthal, B.M., Telford, S.R., Spielman, A., Hartl, D.L. and Ayala, F.J. (1997) Heterogeneity of the Internal Transcribed Spacer (ITS-2) Region within Individual Deer Ticks. Insect Molecular Biology, 6, 123-129. http://onlinelibrary.wiley.com/doi/10.1111/j.1365-2583.1997.tb00080.x/abstract

[30] Simon, K. and Weiß, M. (2008) Intragenomic Variation of Fungal Ribosomal Genes Is Higher than Previously Thought. Molecular Biology and Evolution, 25, 2251-2254. http://dx.doi.org/10.1093/molbev/msn188

[31] Keller, I., Chintauan-Marquier, I., Veltsos, P. and Nichols, R.A. (2006) Ribosomal DNA in Grasshopper Podisma pedestris: Escape from Concerted Evolution. Genetics, 174, 863-874. http://www.genetics.org/content/174/2/863.full.pdf+html

[32] Anstead, J.A., Burd, J.D. and Shufran, K.A. (2002) Mitochondrial DNA Sequence Divergence among Schizaphisgraminumisolates from Non-Cultivated Hosts: Haplotypes and Host Associations. Bulletin of Entomological Research, 92, $17-24$.

[33] Lushai, G., Markovitch, O. and Loxdale, H.D. (2002) Host-Based Genotype Variation in Insects Revisited. Bulletin of Entomological Research, 92, 159-164. http://dx.doi.org/10.1079/BER2001138

[34] Boulding, E.C. (1998) Molecular Evidence against Phylogenetically Distinct Host Races of the Pea Aphid (Acyrthosiphon pisum). Genome, 41, 769-775. http://dx.doi.org/10.1139/g98-094

[35] Simon, J.C., Delmotte, F., Rispe, C. and Crease, T. (2003) Phylogenetic Relationships between Parthenogens and Their Sexual Relatives: The Possible Routes to Parthenogenesis in Animals. Biological Journal of the Linnean Society, 79, 151-163. http://dx.doi.org/10.1046/j.1095-8312.2003.00175.x

[36] Wilson, A.C.C., Sunnucks, P. and Hales, D.F. (2003) Heritable Genetic Variation and Potential for Adaptive Evolution in Asexual Aphids (Aphidoidea). Biological Journal of the Linnean Society, 79, 115-135. http://dx.doi.org/10.1046/j.1095-8312.2003.00176.x

[37] Sunnucks, P., De Barro, P.J., Lushai, G., McLean, N. and Hales, D. (1997) Genetic Structure of an Aphid Studied Using Microsatellites: Cyclic Parthenogenesis, Differentiated Lineages and Host Specialization. Molecular Ecology, 6, 1059-1073. http://dx.doi.org/10.1046/j.1365-294X.1997.00280.x

[38] Delmotte, F., Sabater-Muñoz, B., Prunier-Leterme, N., Latorre, A., Sunnucks, P., Rispe, C. and Simon, J.C. (2003) Phylogenetic Evidences for Hybrid Origins of Asexual Lineages in an Aphid Species. Evolution, 57, 1291-1303. http://dx.doi.org/10.1111/j.0014-3820.2003.tb00337.x

[39] Mandrioli, M., Manicardi, G.C., Bizzaro, D. and Bianchi, U. (1999) NOR Heteromorphism within a Parthenogenetic Lineage of the Aphid Megoura viciae. Chromosome Research, 7, 157-162. http://dx.doi.org/10.1023/A:1009215721904

[40] Loxdale, H.D. and Lushai, G. (2003) Rapid Changes in Clonal Lines: The Death of a "Sacred Cow". Biological Journal of Linnean Society, 79, 3-16. http://dx.doi.org/10.1046/j.1095-8312.2003.00177.x 
Scientific Research Publishing (SCIRP) is one of the largest Open Access journal publishers. It is currently publishing more than 200 open access, online, peer-reviewed journals covering a wide range of academic disciplines. SCIRP serves the worldwide academic communities and contributes to the progress and application of science with its publication.

Other selected journals from SCIRP are listed as below. Submit your manuscript to us via either submit@scirp.org or Online Submission Portal.
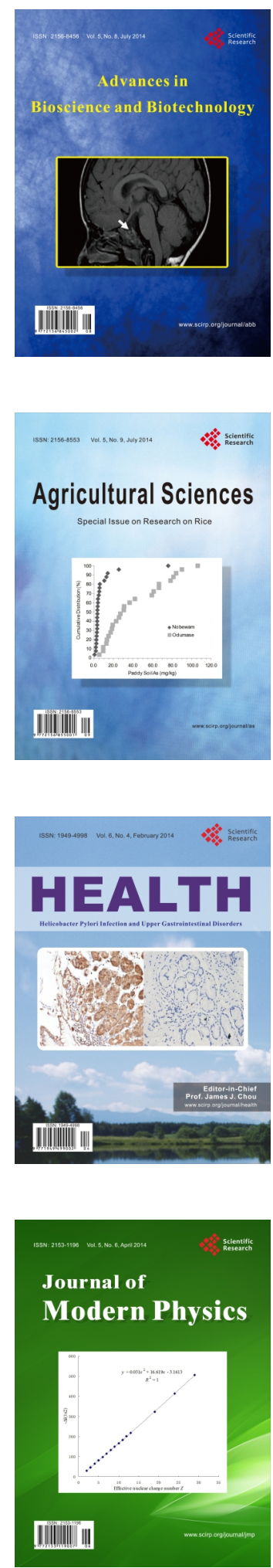
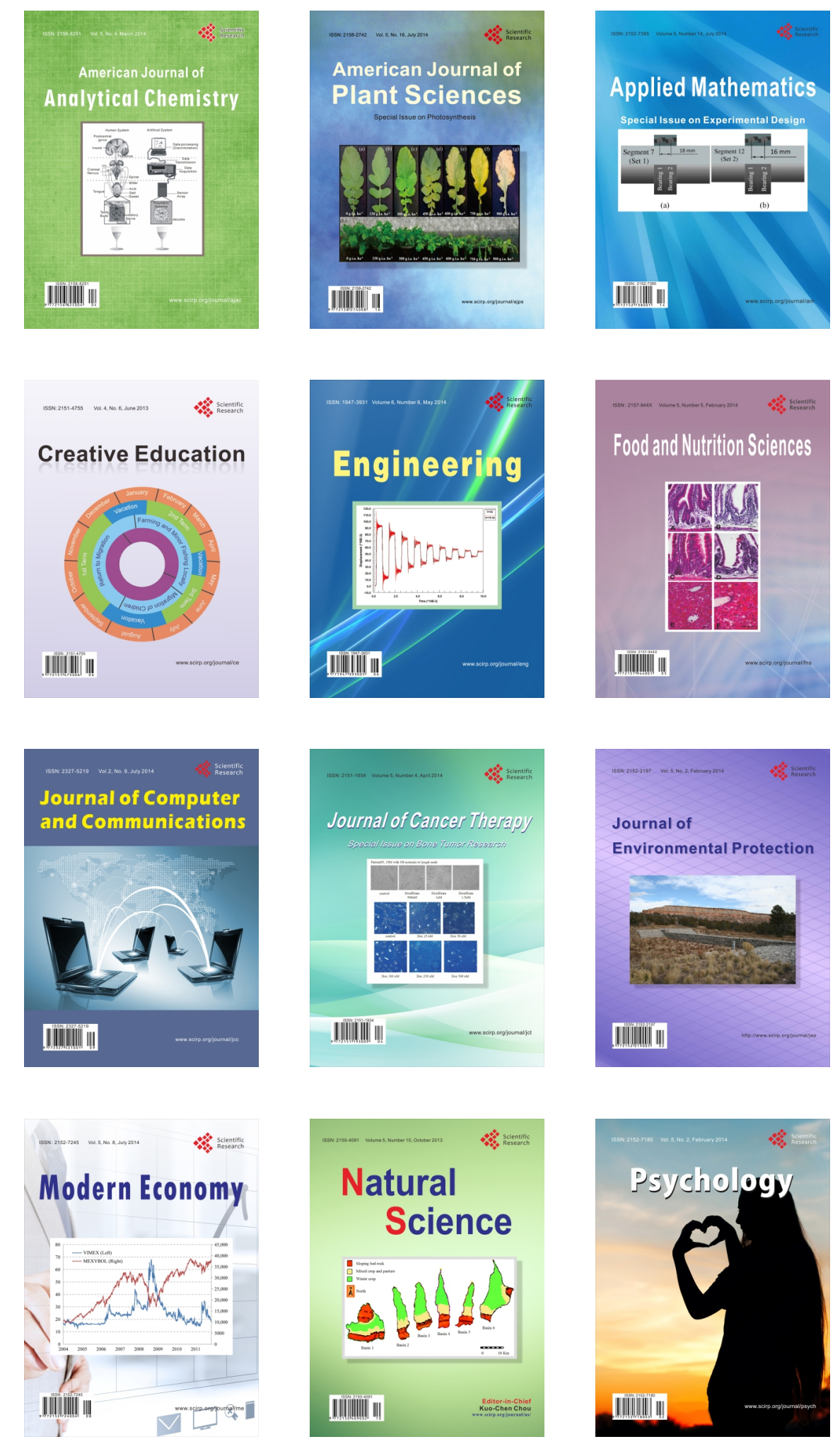